\title{
Mechanistic Insights into a Chiral Phosphoric Acid-Catalyzed Asymmetric Pinacol Rearrangement
}

\author{
Bruno N. Falcone, ${ }^{\dagger}$ Matthew N. Grayson*, and Juan B. Rodriguez ${ }^{\dagger}$ \\ †Departamento de Química Orgánica and UMYMFOR (CONICET-FCEyN), Facultad de Ciencias Exactas y Naturales, \\ Universidad de Buenos Aires, Pabellón 2, Ciudad Universitaria, C1428EHA, Buenos Aires, Argentina \\ *Department of Chemistry, University of Bath, Claverton Down, Bath, BA2 7AY, United Kingdom \\ Supporting Information Placeholder
}

\begin{abstract}
The first catalytic enantioselective pinacol rearrangement was reported by Antilla and co-workers in 2010. The reaction was catalyzed by a chiral phosphoric acid and resulted in high levels of enantioselectivity (up to $96 \% e e$ ). The present study uses Density Functional Theory to investigate the mechanism and origins of stereoselectivity of this important reaction and to explain the difference in selectivity between different catalysts. An $\mathrm{OH} \cdots \mathrm{O}$ hydrogen bond between the intermediate indolyl alcohol and the phosphate group from the catalyst together with a $\mathrm{CH} \cdots \mathrm{O}$ hydrogen bond between the indole and the phosphate group were observed in the preferred activation mode for the stereodetermining [1,2]-aryl shift. A stronger $\mathrm{CH}^{\cdots} \mathrm{O}$ interaction in the major transition state was found to contribute to the high levels of enantioselectivity. A more bulky catalyst (TRIP) was found to impede the formation of the key $\mathrm{CH} \cdots \mathrm{O}$ interaction, leading to lower levels of enantioselectivity.
\end{abstract}

\section{INTRODUCTION}

The pinacol rearrangement ${ }^{1}$ is a Brønsted acid-catalyzed process which involves the dehydration of a vicinal diol followed by a [1,2]-alkyl, [1,2]-aryl or hydride shift. Although this reaction has been known for over a century, its use has been limited ${ }^{2}$ due to issues with regioselectivity arising from the possible formation of multiple carbocations. Instead, most applications have exploited the related semipinacol rearrangement, which leads to the generation of more predictable carbocations. ${ }^{3}$ A recent advance in the development of the pinacol rearrangement came from Antilla and co-workers, ${ }^{4}$ who reported the first catalytic enantioselective variant (Figure 1). The reaction catalyzed by chiral phosphoric acid $(R)-\mathbf{4}$ proceeds with high yield (83$99 \%$ ) and enantioselectivity (91-96\%) on indolyl substrates. This methodology has been exploited in the key step towards the total synthesis of Hopeanol and Hopeahainol A.

In this study, we have utilized computational methods to provide a detailed mechanistic insight into this important reaction. The origins of the enantioselectivity and the performance of different catalysts were explored. We have used previous computational studies on the mechanism of the uncatalyzed pinacol rearrangement to guide our search for transition states (TSs). ${ }^{6}$ Other computational studies which have analyzed key interactions in TSs of similar reactions catalyzed by chiral phosphoric acids guided our search for likely activation modes. ${ }^{7-10}$<smiles>[R][R]C([R])(O)C(O)c1cn([R])c2ccc([R])cc12</smiles>

1

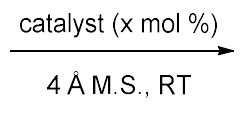<smiles>[R]C(=O)C([R])c1cn([R])c2ccc([R])cc12</smiles>

2

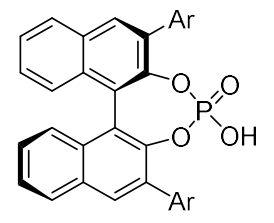

(R)-3: $\mathrm{Ar}=2,4,6-(i \mathrm{Pr})_{3} \mathrm{C}_{6} \mathrm{H}_{2}$

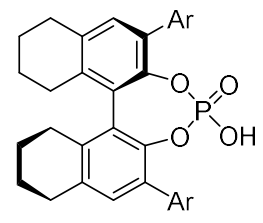

(R)-4: $\mathrm{Ar}=1$-naphthyl

\begin{tabular}{|c|c|c|c|}
\hline \multicolumn{4}{|c|}{ Reported substituents: } \\
\hline \multicolumn{4}{|l|}{$\mathrm{R}^{1}=\mathrm{Me}, \mathrm{Bn}$, Allyl } \\
\hline \multirow{2}{*}{\multicolumn{4}{|c|}{$\begin{aligned} \mathrm{R}^{2}= & \mathrm{Ph}, 4-\mathrm{FC}_{6} \mathrm{H}_{4}, 4-\mathrm{ClC}_{6} \mathrm{H}_{4}, 4-\mathrm{MeC}_{6} \mathrm{H}_{4}, 4-\mathrm{MeOC}_{6} \mathrm{H}_{4}, \\
& \text { 3,5- }-\mathrm{Me}_{2} \mathrm{C}_{6} \mathrm{H}_{3}, \text { 2-naphthyl }\end{aligned}$}} \\
\hline & & & \\
\hline \multicolumn{4}{|c|}{$\mathrm{R}^{3}=\mathrm{H}, \mathrm{F}, \mathrm{Cl}, \mathrm{Br}, \mathrm{Me}, \mathrm{MeO}$} \\
\hline \multicolumn{4}{|c|}{ Key Conditions $\left(\mathbf{R}^{1}=\mathbf{M e}, \mathbf{R}^{2}=\mathbf{P h}, \mathbf{R}^{3}=\mathbf{H}\right)$ : } \\
\hline Catalyst $(x \mathrm{~mol} \%)$ & Solvent & Yield (\%) & $e e(\%)$ \\
\hline$(R)-\mathbf{3}(10)$ & toluene & 93 & 70 \\
\hline$(R)-4(10)$ & toluene & 93 & 93 \\
\hline$(R)-4(2.5)$ & benzene & 94 & 96 \\
\hline
\end{tabular}

Figure 1. Reaction scope and key conditions in the asymmetric pinacol rearrangement reported by Antilla and co-workers. ${ }^{4}$ 


\section{COMPUTATIONAL METHODS}

We have performed DFT calculations with Gaussian $09^{11}$ using the B3LYP and M06-2 $\mathrm{X}^{12}$ functionals. An ultrafine integration grid was used for all calculations. Single point energies ${ }^{13}$ were obtained for the optimized structures using the M06-2X functional with the polarized, triple-zeta valence quality def2-TZVPP basis $\operatorname{set}^{14}$ and the SMD $^{15}$ solvent model. Since a large number of total conformations were explored (87 structures), we have reduced the conformational flexibility of the system by utilizing a model catalyst for (R)-4 with the cyclohexyl rings removed, in order to reduce the computational cost. In a previous study, ${ }^{16}$ the removal of similar external rings was shown to yield valid results. The validity of this approximation was confirmed by comparing the results of the optimizations including and excluding this ring. Details in the Supplementary Information.

The following strategy was taken to explore the conformations of the competing TSs and to explain the origin of the selectivity. First, all different conformations of the substrate in the TS (labeled TS-A, TS-B, TS-C and TS-D) were considered (Figure 3). The optimizations were performed in the following manner: (i) all structures were optimized with B3LYP/6-31G*, followed by single point energy calculations with M06-2X/def2-TZVPP in solvent (SMD), (ii) then the lowest energy TS structure for the minor and major pathways of each substrate conformation (8 conformations in total) was re-optimized with M06-2X/6$31 \mathrm{G}^{*}$, followed by single point energy calculations with M06-2X/def2-TZVPP in solvent (SMD). Once conformation TS-A was established as the lowest in energy, we reoptimized all structures TS-A with M06-2X/6-31G*, followed by single point energy calculations with M062X/def2-TZVPP in solvent (SMD). The use of several Popletype basis sets and the effect of solvent were explored, confirming the validity of the results obtained with $6-31 G^{*}$ in the gas phase. Details in the Supplementary Information.

An extensive conformational search was carried out to find all relevant TS conformations. 4 ns Molecular Dynamics (MD) simulations at $500 \mathrm{~K}$ were performed with the sander module of AmberTools, ${ }^{17}$ using gasteiger ${ }^{18}$ charges and GAFF. ${ }^{19}$ This temperature was used to facilitate the crossing of rotational barriers. The three reacting carbon atoms were fixed in the TS geometry previously determined with DFT. All different 1-naphthyl arrangements were considered. The $\mathrm{H}$-bond between the $\mathrm{OH}$ group of the substrate and the phosphate group of the catalyst was restrained at $1.79 \AA$ to avoid the dissociation of the catalytic complex. The resulting 200 MD frames were minimized with sander and then clustered using the hieragglo algorithm as implemented in the cpptraj module of AmberTools, with a minimum distance between clusters of $2.0 \AA$. Independent conformational searches were carried out for each substrate conformation TS-A, TS-B, TS-C and TS-D.

\section{RESULTS AND DISCUSSION}

The proposed mechanism ${ }^{4}$ of the reaction proceeds via an initial dehydration of the indolyl alcohol $\mathbf{1}$ followed by the pinacol rearrangement of intermediate B (Figure 2). As a first step towards gaining insight into the mechanism of the reaction, different activation modes and substrate geometries for the reaction of intermediate $\mathbf{B}$ were considered.

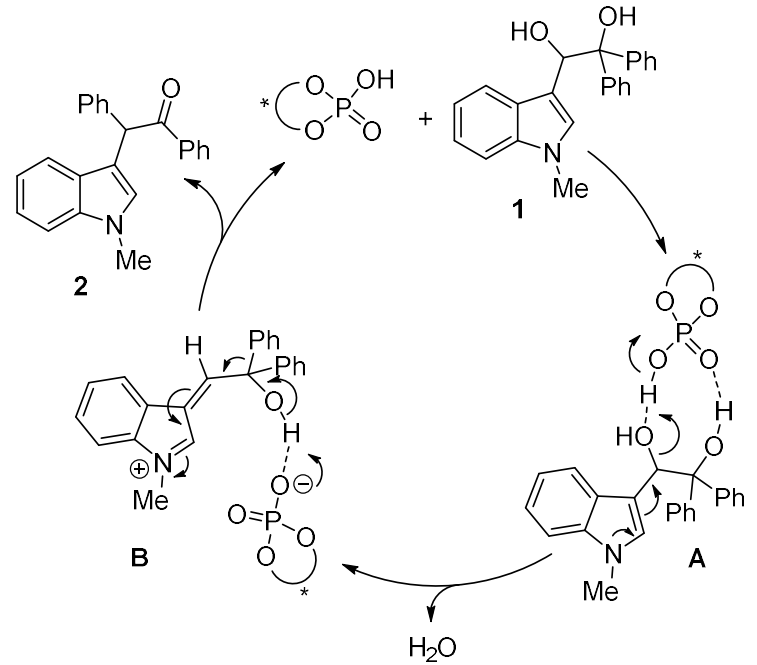

Figure 2. Proposed mechanism of the asymmetric pinacol rearrangement. ${ }^{4}$

Four different substrate geometries TS-A, TS-B, TS-C and TS-D were investigated, with different relative orientations of the $\mathrm{H}_{1}$ and $\mathrm{H}_{2}$ atoms and of the $\mathrm{H}_{2}$ atom and the $\mathrm{OH}$ group, and are shown in Figure 3 in order of increasing energy. Conformation TS-A corresponds to the lowest energy pathway, and 27 TS structures were located. The lowest energy structures leading to the major and minor products show the formation of an $\mathrm{OH} \cdots \mathrm{OP}$ hydrogen bond between the $\mathrm{OH}$ of the substrate and the phosphate, and a $\mathrm{CH} \cdots \mathrm{OP}$ hydrogen bond between the indole hydrogen $\mathrm{H}_{1}$ and the phosphate. Conformation TS-B (15 TS structures located) was found to be $3.1 \mathrm{kcal} \mathrm{mol}^{-1}$ higher in energy for the major pathway, and $3.0 \mathrm{kcal} \mathrm{mol}^{-1}$ for the minor pathway. These structures do not show an H-bond between hydrogen $\mathrm{H}_{1}$ and the phosphate but they do show an H-bond between hydrogen $\mathrm{H}_{2}$ and the phosphate. Conformation TS-C (22 TS structures located) was found to be $6.2 \mathrm{kcal} \mathrm{mol}^{-1}$ higher in energy for the major pathway, and $3.1 \mathrm{kcal} \mathrm{mol}^{-1}$ for the minor pathway. These structures show the formation of $\mathrm{H}$ bonds between hydrogen $\mathrm{H}_{1}$ and the phosphate and between hydrogen $\mathrm{H}_{2}$ and the phosphate, although with longer bond distances. Conformation TS-D (23 TS structures located) was found to be $7.4 \mathrm{kcal} \mathrm{mol}^{-1}$ above the lowest energy conformation for the major pathway, and $4.7 \mathrm{kcal} \mathrm{mol}^{-1}$ for the minor pathway. This more hindered conformation prevents the formation of the secondary $\mathrm{H}$-bonds between the phosphate and hydrogens $\mathrm{H}_{1}$ and $\mathrm{H}_{2}$. H-bond distances and angles are summarized in Table 1. A clear trend is observed: the primary $\mathrm{OH} \cdots \mathrm{OP} \mathrm{H}$-bond becomes longer moving from conformation TS-A to TS-B and to TS-C; and although this primary $\mathrm{H}$-bond is of similar length in conformations TS-A and TS-D, this latter conformation impedes the formation of the secondary $\mathrm{H}$-bond interactions. As these alternative conformations TS-B, TS-C and TS-D are at least $3.0 \mathrm{kcal} \mathrm{mol}^{-1}$ in energy above the lowest energy conformation TS-A, they are not expected to be significant in terms of the reaction mechanism. 
TS-A-major

$\Delta \Delta G^{\ddagger}=0 \mathrm{kcal} \mathrm{mol}^{-1}$
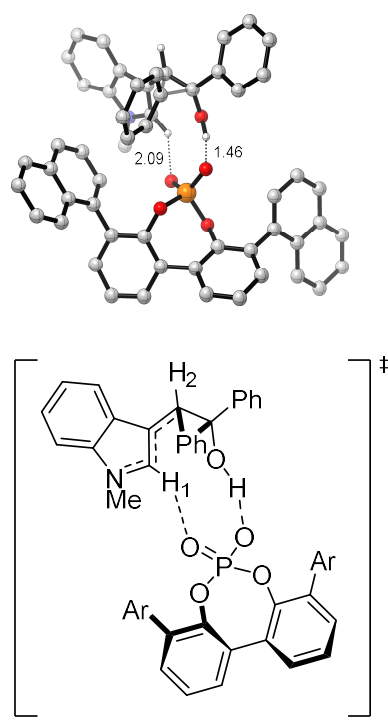

TS-C-major

$\Delta \Delta G^{\ddagger}=+6.2 \mathrm{kcal} \mathrm{mol}^{-1}$
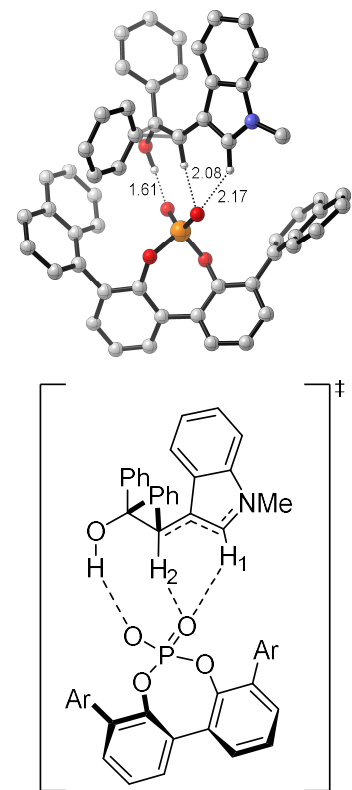

TS-B-major

$\Delta \Delta G^{\ddagger}=+3.1 \mathrm{kcal} \mathrm{mol}^{-1}$
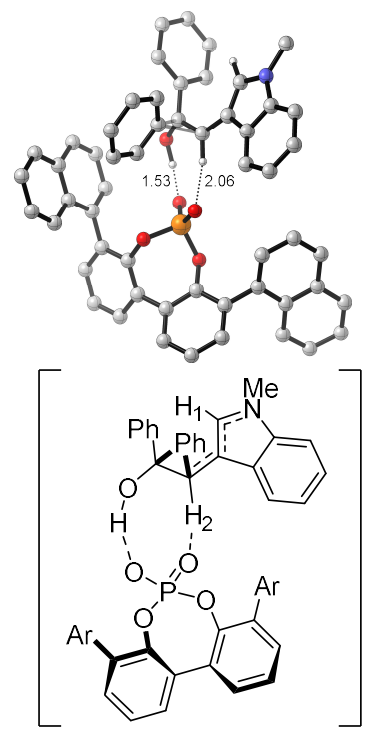

TS-D-major

$\Delta \Delta G^{\ddagger}=+7.4 \mathrm{kcal} \mathrm{mol}^{-1}$
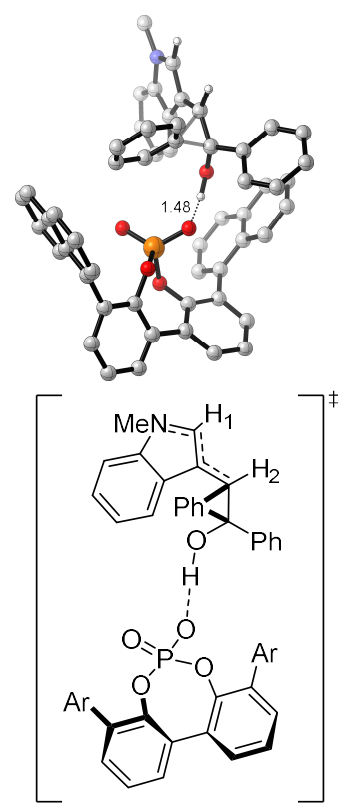

Ar = 1-naphthyl

Figure 3. TS structures for the different conformations TS-A, TS-B, TS-C and TS-D considered for the substrate in the major pathway with catalyst (R)-4, M06-2X/def2-TZVPPSMD(benzene)//M06-2X/6-31G*. Key hydrogen bonding interactions are shown, with their corresponding bond distances in $\AA$. Noncritical hydrogen atoms omitted for clarity.

Once conformation TS-A was established as the lowest in energy, we sought to explain the origins of the enantioselectivity. All TS-A structures were re-optimized with M06-2X/6-31G*. The lowest energy structures show the formation of the key $\mathrm{OH} \cdots \mathrm{OP}$ and $\mathrm{CH}_{1} \cdots \mathrm{OP}$ hydrogen bonding interactions between the substrate and the catalyst, with the major TS favored over the minor TS by $1.2 \mathrm{kcal} \mathrm{mol}^{-1}$ (Figure 4). The C-C breaking bond (1.71 $\AA$ in TS-1-major and $1.73 \AA$ in TS-1-minor) is slightly shorter

than the $\mathrm{C}-\mathrm{C}$ forming bond (1.84 $\AA$ for TS-1-major and $1.83 \AA$ for TS-1-minor). Overall, 6 TSs were found for the major pathway and 10 for the minor one. The $\mathrm{OH} \cdots \mathrm{OP}$ interaction is present in all TSs while the $\mathrm{CH}_{1} \cdots \mathrm{OP}$ one is important for the stabilization of the TSs: conformations without the latter interaction were found to be $3.1 \mathrm{kcal} \mathrm{mol}^{-1}$ above the lowest energy conformation for the major pathway, and $1.8 \mathrm{kcal} \mathrm{mol}^{-1}$ for the minor pathway.

\begin{tabular}{|c|c|c|c|c|c|c|c|}
\hline & \multicolumn{2}{|c|}{ OH $\cdots O P$} & \multicolumn{2}{|c|}{$\mathrm{CH}_{1} \cdots \mathrm{OP}$} & \multicolumn{2}{|c|}{$\mathrm{CH}_{2} \cdots \mathrm{OP}$} & \multirow[t]{2}{*}{$\Delta \Delta G^{\ddagger}$} \\
\hline & $(\AA ̊)$ & $\left({ }^{\circ}\right)$ & (§̊) & $\left({ }^{\circ}\right)$ & $(\AA ̊)$ & $\left({ }^{\circ}\right)$ & \\
\hline TS-A-major & 1.46 & 166 & 2.09 & 142 & & & 0.0 \\
\hline TS-A-minor & 1.34 & 172 & 2.04 & 148 & & & 2.0 \\
\hline TS-B-major & 1.53 & 176 & & & 2.06 & 160 & 3.1 \\
\hline TS-B-minor & 1.51 & 172 & & & 2.00 & 170 & 5.0 \\
\hline TS-C-major & 1.61 & 175 & 2.17 & 139 & 2.08 & 154 & 6.2 \\
\hline TS-C-minor & 1.66 & 169 & 2.09 & 147 & 2.26 & 154 & 5.1 \\
\hline TS-D-major & 1.48 & 171 & & & & & 7.4 \\
\hline TS-D-minor & 1.52 & 169 & & & & & 6.7 \\
\hline
\end{tabular}

Table 1. H-bond distances (in $\AA$ ) and angles (in ${ }^{\circ}$ ), and TS energies (in $\mathrm{kcal} \mathrm{mol}^{-1}$ ) observed in the different conformations TS-A, TS-B, TS-C and TS-D for the major and minor TS structures, M06-2X/def2-TZVPP-SMD(benzene)//M06-2X/6$31 \mathrm{G}^{*}$.
TS-1-major

$\Delta \Delta G^{\ddagger}=0 \mathrm{kcal} \mathrm{mol}^{-1}$
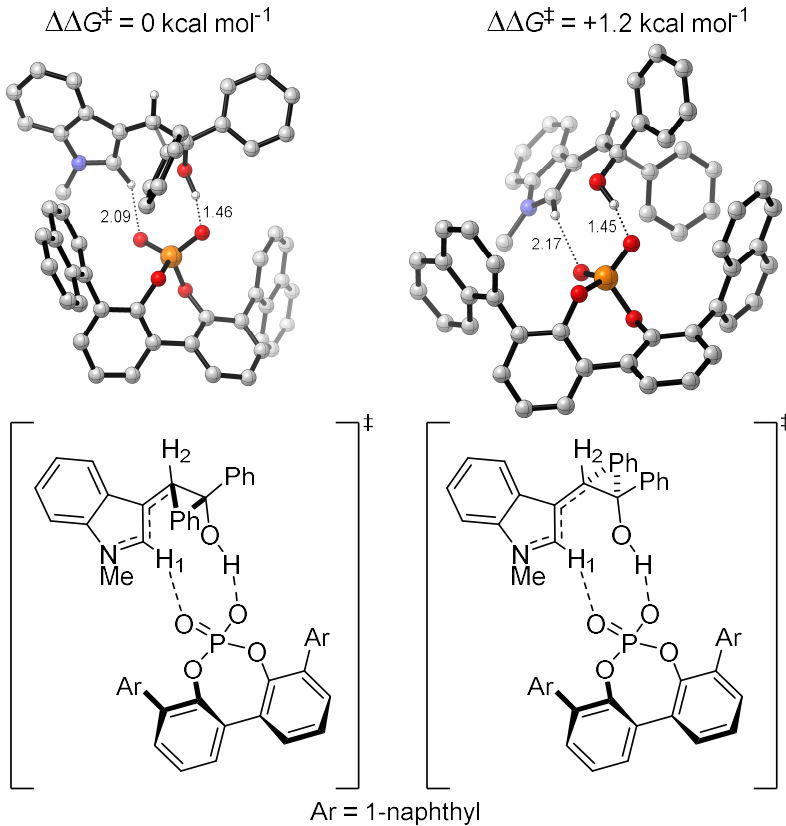

Figure 4. Lowest energy TS structures leading to the major and minor products with catalyst $(R)-4$, M06-2X/def2TZVPP-SMD(benzene)//M06-2X/6-31G*. Bond lengths are shown for the key hydrogen bond interactions between the reacting species and the catalyst. Noncritical hydrogen atoms omitted for clarity.

As no obvious steric interactions are present in the major or the minor TSs, a Natural Bond Orbital analysis was carried out to account for the greater stabilization of TS-1major relative to TS-1-minor (Figure 5). It was found that a 
stronger $\mathrm{H}$-bond is formed between the $\mathrm{C}-\mathrm{H}_{1}$ and $\mathrm{O}-\mathrm{P}$ groups, as this interaction accounts for $5.9 \mathrm{kcal} \mathrm{mol}^{-1}$ in TS1-major vs. $4.0 \mathrm{kcal} \mathrm{mol}^{-1}$ in TS-1-minor. The largest orbital interaction occurs between the $\mathrm{C}-\mathrm{H}_{1}$ antibonding orbital from the indole ring and the O-P oxygen lone pair, representing $2.7 \mathrm{kcal} \mathrm{mol}^{-1}$ in the major TS but only $1.5 \mathrm{kcal} \mathrm{mol}^{-1}$ in the minor TS.

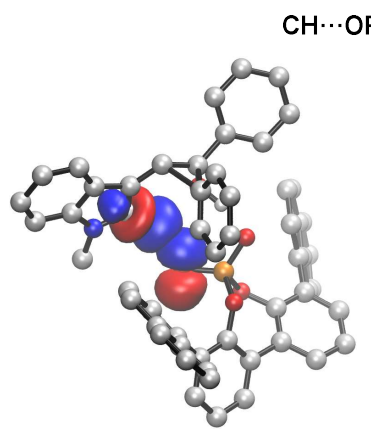

TS-1-major

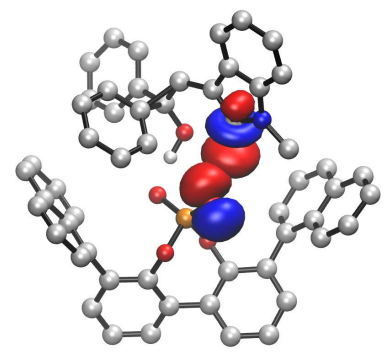

TS-1-minor
Figure 5. Natural Bond Orbital analysis showing the key secondary orbital interactions for the TS-1-major (left) and TS1-minor (right) lowest energy TSs with catalyst $(R)-4$, M062X/def2-TZVPP//M06-2X/6-31G*. See Figure 4 for the interactions shown using chemical drawings. Noncritical hydrogen atoms omitted for clarity.

The experimental results showed that catalyst $(R)-3$ achieved a lower ee than catalyst $(R)-4(70 \%$ vs $93 \%$ in toluene, Figure 1). This is somewhat surprising since catalyst $(R)-\mathbf{3}$ usually achieves greater selectivities given the larger steric demands of the 3 and 3 ' substituents. ${ }^{20-23}$ To rationalize this result, TSs were located for catalyst $(R)-\mathbf{3}$ with M06-2X/6-31G* followed by M06-2X/def2-TZVPP single point energies calculated in toluene (SMD solvent model) and were compared with those obtained for $(R)-\mathbf{4}$. Two TSs were found for the major and minor pathways each. The lowest energy TSs (Figure 6) were found to be close in energy, therefore explaining the lower selectivity of the reaction with this catalyst (the TS leading to the major product was found to be $0.3 \mathrm{kcal} \mathrm{mol}^{-1}$ lower in energy than the minor one). The orientation of the substrate with respect to the catalyst in the TSs are different: in the reaction catalyzed by $(R)-4$ the migrating phenyl ring points towards the catalyst (Figure 4), whereas in the reaction catalyzed by $(R)-3$ it points away from the catalyst given the greater steric size of the substituents. This new conformation impedes the formation of the secondary interactions that accounted for the difference in energies in the major and minor catalysts for $(R)-4$, i.e. the $\mathrm{CH}_{1} \cdots \mathrm{O}$ hydrogen bonding interaction between the indole ring and the phosphate group. This secondary interaction was not present in any of the TSs found for $(R)-3$.
3-TS-1-major

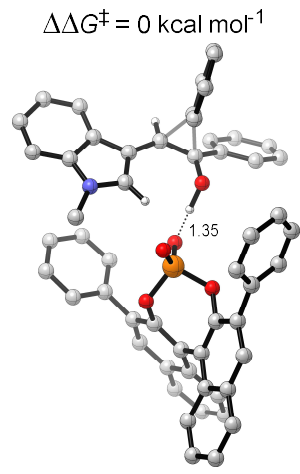

3-TS-1-minor

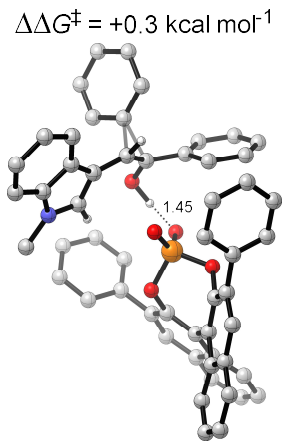

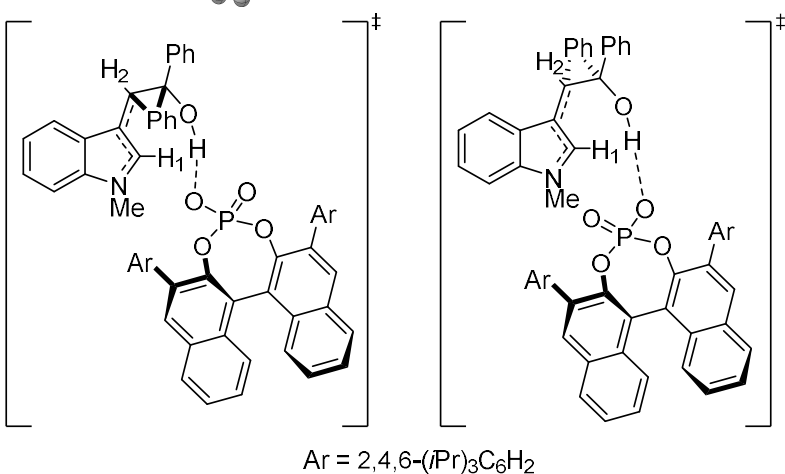

Figure 6. Lowest energy TS structures leading to the major and minor products with catalyst $(R)-3$, M06-2X/def2-TZVPP$\mathrm{SMD}$ (toluene)//M06-2X/6-31G*. $i \operatorname{Pr}$ groups and noncritical hydrogen atoms omitted for clarity.

\section{CONCLUSIONS}

In conclusion, DFT calculations were performed on the chiral phosphoric acid-catalyzed asymmetric pinacol rearrangement. Different conformations of the substrate were evaluated and conformation TS-A (Figure 3) led to the lowest energy TS since it allows for the formation of the shortest $\mathrm{OH} \cdots \mathrm{OP} \mathrm{H}$-bond and the formation of a secondary $\mathrm{H}$-bond between the indole hydrogen $\mathrm{CH}_{1}$ and the phosphate. The origins of the enantioselectivity were investigated for conformation TS-A and the results suggest that there are two key interactions involved in the TS: an H-bond between the alcohol and the phosphate group and a $\mathrm{CH}_{1} \cdots \mathrm{OP}$ interaction between the indole and the phosphate group. The difference in strength of the $\mathrm{CH}_{1} \cdots \mathrm{OP}$ interaction accounts for the differences in energies for the pathways leading to the major and minor products, with TS-1-major being $1.2 \mathrm{kcal} \mathrm{mol}^{-1}$ lower than TS-1-minor. A Natural Bond Orbital Analysis was carried out and it provided a detailed quantitative explanation for the differences in energies between the major and minor TSs. In the reaction catalyzed by the more bulky catalyst $(R)-\mathbf{3}$, the substrate adopts a different orientation in the TS, with the migrating phenyl ring pointing away from the catalyst, therefore impeding the formation of the $\mathrm{CH}_{1} \cdots \mathrm{OP}$ interaction and leading to lower levels of enantioselectivity. These results provide valuable insight into the mechanism of this reaction and can be used in the design of more selective catalysts for this and related transformations. 


\section{SUPPORTING INFORMATION}

Complete list of authors in the Gaussian 09 reference; Cartesian coordinates, energies, and number of imaginary frequencies of all stationary points and values of imaginary frequencies of all transition structures. This material is available free of charge via the Internet at http://pubs.acs.org.

\section{AUTHOR INFORMATION}

Corresponding Author

*E-mail: M.N.Grayson@bath.ac.uk

ORCID

Bruno N. Falcone: 0000-0003-0114-9213

Matthew N. Grayson: 0000-0003-2116-7929

Juan B. Rodriguez: 0000-0002-5180-096X

Notes

The authors declare no competing financial interests.

\section{ACKNOWLEDGEMENTS}

This work was supported by Grants from Consejo Nacional de Investigaciones Científicas y Técnicas (PIP 112-201501-00631 CO), Agencia Nacional de Promoción Científica y Tecnológica (PICT-2015-1349) and the University of Buenos Aires (20020170100067BA), to J.B.R. The authors would like to thank Centro de Cómputos de Alto Rendimiento (CeCAR) for granting use of computational resources which allowed us to perform the experiments included in this work. M.N.G. thanks Girton College, Cambridge (Research Fellowship) and the University of Bath for financial support. Dr. Zhongyue Yang is thanked for his helpful discussions regarding this work.

\section{REFERENCES}

(1) Fittig, R. Ueber Einige Derivate des Acetons. Justus Liebigs Ann. Chem. 1860, 114, 54-63.

(2) Kurti, L.; Czakó, B. Pinacol and Semipinacol Rearrangement. In Strategic Applications of Named Reactions in Organic Chemistry; Academic Press/Elsevier: San Diego, 2005; pp 350-351.

(3) Coveney, D. J. The Semipinacol and Other Rearrangements. In Comprehensive Organic Synthesis, Vol. 3; Trost, B. M., Fleming, I., Eds.; Pergamon: Oxford, 1991; pp 777-801.

(4) Liang, T.; Zhang, Z.; Antilla, J. C. Chiral Brønsted Acid Catalyzed Pinacol Rearrangement. Angew. Chemie, Int. Ed. 2010, 49 (50), 9734-9736.

(5) Snyder, S. A.; Thomas, S. B.; Mayer, A. C.; Breazzano, S. P. Total Syntheses of Hopeanol and Hopeahainol A Empowered by a Chiral Brønsted Acid Induced Pinacol Rearrangement. Angew. Chemie, Int. Ed. 2012, 51 (17), 4080-4084.

(6) Nakamura, K.; Osamura, Y. Theoretical Study of the Reaction Mechanism and Migratory Aptitude of the Pinacol Rearrangement. J. Am. Chem. Soc. 1993, 115 (20), 91129120

(7) Simón, L.; Goodman, J. M. Mechanism of BINOLPhosphoric Acid-Catalyzed Strecker Reaction of Benzyl Imines. J. Am. Chem. Soc. 2009, 131 (11), 4070-4077.

(8) Grayson, M. N.; Pellegrinet, S. C.; Goodman, J. M. Mechanistic Insights into the BINOL-Derived Phosphoric
Acid-Catalyzed Asymmetric Allylboration of Aldehydes. $J$. Am. Chem. Soc. 2012, 134 (5), 2716-2722.

(9) Overvoorde, L. M.; Grayson, M. N.; Luo, Y.; Goodman, J. M. Mechanistic Insights into a BINOL-Derived Phosphoric AcidCatalyzed Asymmetric Pictet-Spengler Reaction. J. Org. Chem. 2015, 80 (5), 2634-2640.

(10) Rodríguez, E.; Grayson, M. N.; Asensio, A.; Barrio, P.; Houk K. N.; Fustero, S. Chiral Brønsted Acid-Catalyzed Asymmetric Allyl(propargyl)boration Reaction of Ortho Alkynyl Benzaldehydes: Synthetic Applications and Factors Governing the Enantioselectivity. ACS Catal. 2016, 6 (4), 2506-2514.

(11) Frisch, M. J.; et al. Gaussian 09; Gaussian Inc.: Wallingford CT, 2013.

(12) Zhao, Y.; Truhlar, D. G. Density Functionals with Broad Applicability in Chemistry. Acc. Chem. Res. 2008, 41 (2), 157-167.

(13) Simón, L.; Goodman, J. M. How Reliable Are DFT Transition Structures? Comparison of GGA, Hybrid-Meta-GGA and Meta-GGA Functionals. Org. Biomol. Chem. 2011, 9 (3), 689-700.

(14) Weigend, F.; Ahlrichs, R. Balanced Basis Sets of Split Valence, Triple Zeta Valence and Quadruple Zeta Valence Quality for $\mathrm{H}$ to Rn: Design and Assessment of Accuracy. Phys. Chem. Chem. Phys. 2005, 7 (18), 3297-3305.

(15) Marenich, A. V. Cramer, C. J.; Truhlar, D. G. Universal Solvation Model Based on Solute Electron Density and on a Continuum Model of the Solvent Defined by the Bulk Dielectric Constant and Atomic Surface Tensions. J. Phys. Chem. B 2009, 113 (18), 6378-6396.

(16) Grayson, M. N.; Goodman, J. M. Understanding the Mechanism of the Asymmetric Propargylation of Aldehydes Promoted by 1,1'-bi-2-Naphthol-Derived Catalysts. J. Am. Chem. Soc. 2013, 135 (16), 6142-6148.

(17) Roe, D. R.; Cheatham III, T. E. PTRAJ and CPPTRAJ: Software for Processing and Analysis of Molecular Synamics Trajectory Data. J Chem. Theory Comput. 2013, 9 (7), 3084 3095

(18) Gasteiger, J.; Marsili, M. A New Model for Calculating Atomic Charges in Molecules. Tetrahedron Lett. 1978, 19 (34), 3181-3184.

(19) Wang, J. M.; Wolf, R. M.; Caldwell, J. W.; Kollman, P. A.; Case, D. A. Development and Testing of a General Amber Force Field. J. Comput. Chem. 2004, 25 (9), 1157-1174.

(20) Akiyama, T.; Itoh, J.; Fuchibe, K. Recent Progress in Chiral Brønsted Acid Catalysis. Adv. Synth. Catal. 2006, 348 (9), 999-1010.

(21) Zamfir, A.; Schenker, S.; Freund, M.; Tsogoeva, S. B. Chiral BINOL-Derived Phosphoric Acids: Privileged Brønsted Acid Organocatalysts for C-C Bond Formation Reactions. Org. Biomol. Chem. 2010, 8 (23), 5262-5276.

(22) Parmar, D.; Sugiono, E.; Raja, S.; Rueping, M. Complete Field Guide to Asymmetric BINOL-Phosphate Derived Brønsted Acid and Metal Catalysis: History and Classification by Mode of Activation; Brønsted Acidity, Hydrogen Bonding, Ion Pairing, and Metal Phosphates. Chem. Rev. 2014, 114 (18), 9047-9153.

(23) Reid, J. P.; Goodman, J. M. Selecting Chiral BINOL-Derived Phosphoric Acid Catalysts: General Model To Identify Steric Features Essential for Enantioselectivity. Chem. Eur. J. 2017, 23 (57), 14248-14260. 
TS-1-major

$\Delta \Delta G^{\ddagger}=0 \mathrm{kcal} \mathrm{mol}^{-1}$

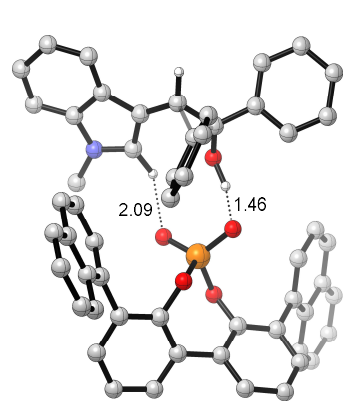

TS-1-minor

$\Delta \Delta G^{\ddagger}=+1.2 \mathrm{kcal} \mathrm{mol}^{-1}$

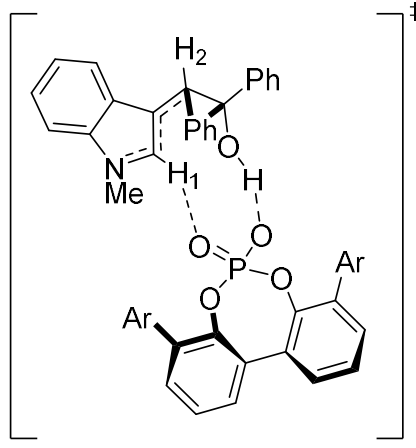

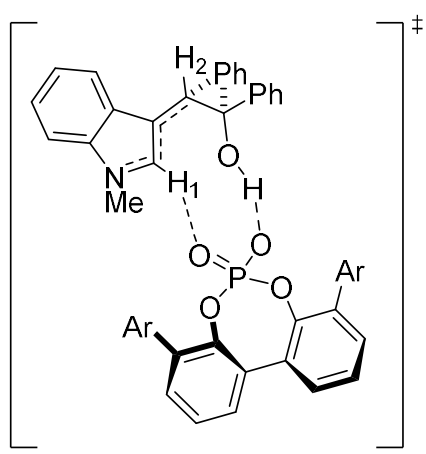

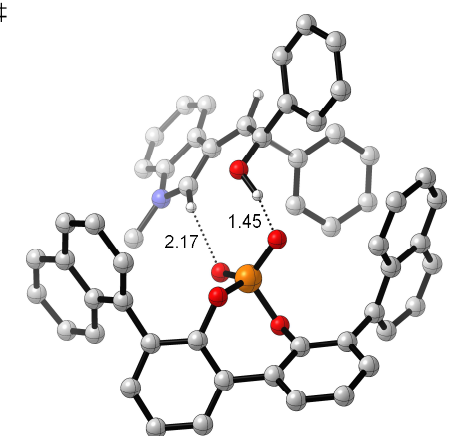

